\title{
Mineração
}

\section{Grau de saponificação de óleos vegetais na flotação seletiva de apatita de minério carbonatítico}

\author{
Jardel Alves de Oliveira \\ Mestrando do PPGEM/UFOP.E-mail: jardelalves@gmail.com \\ José Aurélio Medeiros da Luz \\ Dr., Professor do PPGEM/UFOP. E-mail: jaurelio@demin.ufop.br \\ Eliomar Evaristo Ferreira \\ Dr., Engenheiro Metalurgista do CDM/CVRD.E-mail: eliomar.ferreira@cvrd.com.br
}

\section{Resumo}

Ensaios de flotação, em bancada, de amostras de minério fosfático granulado e friável de Tapira-MG foram efetuados, testando-se diferentes graus de saponificação de três coletores aniônicos: "Hidrocol parcialmente hidrogenado", "Hidrocol sem hidrogenação" (obtidos a partir de soja) e ácido oléico. Os graus de saponificação usados foram de $40 \%, 55 \%, 70 \%, 85 \%$ e $100 \%$. Os ensaios foram feitos em $\mathrm{pH} 9,5$. O óleo de babaçu, também cogitado como coletor, não permitiu grau de saponificação além de $40 \%$, mas serviu de controle da metodologia de quantificação do grau de saponificação. O Hidrocol parcialmente hidrogenado com grau de saponificação de $55 \%$ foi o melhor, em termos de teor e recuperação de fósforo, relação $\mathrm{CaO} / \mathrm{P}_{2} \mathrm{O}_{5}$ e teor de magnésia no concentrado, motivando testes de flotação em estágio de limpeza, sem e com a adição do coletor KE883B, um sulfosuccinato, também em pH 9,5, utilizando-se os óleos com grau de saponificação de $55 \%$. O Hidrocol parcialmente hidrogenado sem KE883B deu melhor resultado. Usouse amido como depressor em todos os ensaios.

Palavras-chave: Rochas fosfáticas, saponificação, ácidos graxos, flotação de apatita.

\begin{abstract}
Bench scale flotation experiments were performed testing three anionic collectors here called "partially hydrogenated Hidrocol", "non hydrogenated Hidrocol" (very similar oils from soybean) and oleic acid, with saponification degrees of $40 \%, 55 \%, 70 \%$, $85 \%$ and $100 \%$, in order to purify carbonatitic phosphate ores from Tapira. The value of flotation $\mathrm{pH}$ was 9.5. A refined babassu oil sample (extracted from the babassu palm seed kernel) did not achieve a saponification degree above $40 \%$. Using the $\mathrm{P}_{2} \mathrm{O}_{5}$ content and recovery, the $\mathrm{CaO} / \mathrm{P}_{2} \mathrm{O}_{5}$ ratio and $\mathrm{MgO}$ content of the concentrate as quality indicators, the best results were achieved with the saponification degree of $55 \%$, for the oils tested. Cleaner lab flotation tests were carried out using the collectors with a saponification degree of 55\%, at pH 9.5, in the absence and in the presence of KE883B (alkyl sulphosuccinate). The best results were obtained to the "partially hydrogenated Hidrocol" in the absence of KE883B. Starch was used as the depressant in all tests.
\end{abstract}

Keywords: Phosphate ore, saponification, fatty acids, apatite flotation. 


\section{Introdução}

Em Tapira, Minas Gerais, a Fosfertil Fertilizantes Fosfatados S/A explota um minério de fosfato associado a carbonatito de chaminé alcalina de grande importância econômica. A concentração desse oximineral, exceto para os denominados ultrafinos, tem sido feita em célula convencional de flotação, empregando-se uma mistura de sais de ácidos graxos obtida através da saponificação do Hidrocol, reagente obtido a partir da borra de óleo de soja.

A saponificação, ou hidrólise alcalina, é uma reação entre óleos e álcalis, sob pressão e aquecimento moderado, que origina, além do glicerol, ácidos graxos na forma de sabões (sais alcalinos). A mistura de sais de ácidos graxos constitui o coletor aniônico mais empregado na concentração de oximinerais por flotação.

A operação de saponificação, na usina do complexo de mineração de Tapira, ocorre de forma contínua, em reatores cilíndricos agitados. A alimentação dos reagentes (água, Hidrocol e hidróxido de sódio) é feita ininterruptamente. A concentração da soda cáustica é ajustada em, aproximadamente, $10 \%$ em massa para ser utilizada na saponificação do Hidrocol e na manutenção do pH em 9,5 na flotação. O óleo de soja chega aos reatores a $35^{\circ} \mathrm{C}$. Dilui-se com água para auxiliar na formação de mistura homogênea. A agitação é feita por impelidores tipo turbina e os reatores são mantidos sob aquecimento moderado. O sabão formado ainda sofre diluição ulterior, a fim de facilitar seu bombeamento para os condicionadores da usina.

O grau de saponificação (conversão) dos óleos vegetais é um dos parâmetros monitorados durante o processo de transformação do óleo vegetal em uma mistura de sais alcalinos de ácidos graxos, mais glicerol. Na flotação industrial, em níveis de saponificação próximos a $100 \%$, ocorre espumação persistente prejudicial ao processo (Peres \& Guimarães, 1999). O glicerol formado auxilia na estabilização do sistema.
O largo emprego dos óleos vegetais, sob a forma de sabões, como coletores na concentração de oxi-minerais, incentivou vários trabalhos, verificando o potencial de diferentes óleos como matérias-primas para coletores, com base nos seus ácidos graxos constituintes (Brandão et alii, 1994; Guimarães et alii, 2005). Entretanto são escassas as pesquisas sobre os efeitos do grau de saponificação dos óleos vegetais na flotação de oximinerais.

Esse trabalho visa a avaliar o efeito do grau de saponificação de diferentes reagentes à base de ácidos graxos na flotação da apatita, através de ensaios de flotação em escala de bancada.

\section{Materiais e métodos}

As amostras de minérios, provenientes do complexo carbonatítico alcalino de Tapira, foram coletadas na usina de beneficiamento de minério da Fosfertil, após as etapas de moagem, separação magnética de baixa intensidade e deslamagens, nos dois circuitos de beneficiamento (granulado e friável). $\mathrm{Na}$ Tabela 1, são apresentados os teores de $\mathrm{P}_{2} \mathrm{O}_{5}, \mathrm{Fe}_{2} \mathrm{O}_{3}, \mathrm{MgO}$ e $\mathrm{CaO}$, das amostras minério, obtidos através de análises químicas via úmida.

Ácido oléico, Hidrocol parcialmente hidrogenado e Hidrocol sem hidrogenação, saponificados com $\mathrm{NaOH}$ a $11,5 \% \mathrm{~m} / \mathrm{v}$ e dosados em $400 \mathrm{~g} / \mathrm{t}$, foram utilizados como coletores. Os graus de saponificação adotados foram de $40 \%$, $55 \%, 70 \%, 85 \%$ e $100 \%$, para os ensaios de flotação aniônica direta da apatita, primeiramente etapa de desbaste rougher e, posteriormente, etapa de limpeza cleaner, sem a adição do coletor

Tabela 1 - Composição química dos minérios fosfáticos de Tapira-MG.

\begin{tabular}{c|c|c|c|c}
\hline \multirow{2}{*}{$\begin{array}{c}\text { Minério } \\
\text { fosfático }\end{array}$} & \multicolumn{4}{|c}{ Teores (\%) } \\
\cline { 2 - 5 } & $\mathbf{P}_{\mathbf{2}} \mathbf{O}_{\mathbf{5}}$ & $\mathrm{Fe}_{\mathbf{2}} \mathbf{O}_{3}$ & $\mathbf{M g O}$ & $\mathbf{C a O}$ \\
\hline Granulado & 9,23 & 15,25 & 1,94 & 13,83 \\
\hline Friável & 11,86 & 24,25 & 2,31 & 17,77 \\
\hline
\end{tabular}
ção do Ke883B, um sulfosuccinato, como descrito por Lima (1986). O óleo de babaçu não alcançou grau de saponificação superior a $40 \%$. O depressor amido de milho foi gelatinizado com $\mathrm{NaOH}$ e dosado em $500 \mathrm{~g} / \mathrm{t}$. Soluções de $\mathrm{NaOH}$ e $\mathrm{HCl}$ (grau de pureza analítica) a $5 \%$ ajustaram o pH em 9,5. A célula de flotação foi a CIMAQ, modelo CFB 1000.

Para a etapa cleaner com KE883B, as dosagens dos coletores foram: $70 \%$ de sabão e $30 \%$ de KE883B, para o minério granulado; $85 \%$ de sabão e $15 \%$ de KE883B, para o friável; essas dosagens representam a proporção mássica dos reagentes, diante da dosagem de coletor adotada.

O grau de saponificação dos óleos vegetais foi determinado baseando-se no procedimento descrito no método AOCS Db-3-48, de determinação de álcali livre em sabões.

Os óleos foram caracterizados através das técnicas: espectroscopia de infravermelho, pelo espectrômetro PerkinElmer modelo 1760X; cromatografia gasosa, pelo cromatógrafo GC9001, Finnigan; e determinações dos índices de acidez (IA), iodo (II), saponificação (IS) e os teores de matéria insaponificá$\operatorname{vel}(\mathrm{MI})$.

\section{Resultados e discussão}

A Tabela 2 apresenta as composições dos óleos vegetais, determinadas através da cromatografia gasosa. Observa-se que houve similaridade nas composições do Hidrocol parcialmente hidrogenado e do Hidrocol sem hidrogenação. Os teores de ácidos graxos insa- sintético Ke883B, e, depois, com a adi- 
Jardel Alves de Oliveira et al.

Tabela 2 - Composição dos óleos vegetais, por cromatografia gasosa.

\begin{tabular}{c|c|c|c|c|c|c}
\hline \multirow{2}{*}{ Óleo } & \multicolumn{7}{c}{ Ácidos graxos (\%) } \\
\cline { 2 - 7 } & $\begin{array}{c}\text { Láurico } \\
\text { C12:0 }\end{array}$ & $\begin{array}{c}\text { Mirístico } \\
\text { C14:0 }\end{array}$ & $\begin{array}{c}\text { Palmítico } \\
\text { C16:0 }\end{array}$ & $\begin{array}{c}\text { Oléico } \\
\text { C18:1(9) }\end{array}$ & $\begin{array}{c}\text { Linoléico } \\
\text { C18:2(9,12) }\end{array}$ & $\begin{array}{c}\text { Linolênico } \\
\text { C18:3(9,12,15) }\end{array}$ \\
\hline Ácido oléico & - & 2,66 & 7,30 & 58,70 & 14,22 & 1,90 \\
\hline Hidrocol hidrogenado & 0,42 & 0,39 & 16,43 & 18,37 & 52,80 & 4,33 \\
\hline Hidrocol sem hidrogenação & 0,30 & 0,46 & 20,28 & 17,56 & 51,06 & 3,87 \\
\hline Óleo de babaçu refinado & 44,31 & 17,62 & 10,48 & 15,87 & 0,11 & - \\
\hline
\end{tabular}

turados do óleo parcialmente hidrogenado são ligeiramente superiores aos teores encontrados para o Hidrocol sem hidrogenação, confirmando as análises de índice de iodo (Tabela 3).

Por sua vez, o ácido oléico apresentou 58,70\% desse ácido e cerca de $14 \%$ de linoléico. A soma de todos os componentes apresentados na Tabela 2 atingiu $85 \%$, indicando a presença de outros ácidos graxos. Isso mostra que esse óleo é uma oleína.

O óleo de babaçu apresentou constituição característica, sendo composto principalmente, por ácido láurico $(44,3$ $\%)$, mirístico $(17,6 \%)$, oléico $(15,9 \%)$ e palmítico $(10,5 \%)$.

Óleos vegetais são apresentados na Tabela 3. O valor de índice de iodo do Hidrocol parcialmente hidrogenado apresenta-se ligeiramente superior ao valor do Hidrocol sem hidrogenação, ao contrário do que se esperava, uma vez que a hidrogenação reduz a quantidade de duplas ligações das cadeias hidrocarbônicas. Entre os dois reagentes, o índice de acidez foi maior para o Hidrocol sem hidrogenação, indicando maior presença de ácidos graxos livres. Os valores de índice de saponificação (IS) e matéria insaponificável foram similares.

No caso da amostra de ácido oléico, o elevado valor do índice de acidez está relacionado à presença de ácidos graxos livres, nesse caso, o ácido oléico; os valores de índice de iodo refletem a presença de duplas ligações entre as moléculas de carbono $(\mathrm{C}=\mathrm{C})$ no compo-

Tabela 3 - Análise química via úmida dos óleos vegetais.

\begin{tabular}{c|c|c|c|c}
\hline Óleo & $\begin{array}{c}\text { IA } \\
\text { (mg KOH/g) }\end{array}$ & $\begin{array}{c}\text { II } \\
\text { (cg l/g) }\end{array}$ & $\begin{array}{c}\text { IS } \\
\text { (mg KOH/g) }\end{array}$ & $\begin{array}{c}\text { MI } \\
\text { (\%) }\end{array}$ \\
\hline Ácido oléico & 201,49 & 97,04 & 201,61 & 0,44 \\
\hline Hidrocol hidrogenado & 134,67 & 115,58 & 191,16 & 3,31 \\
\hline Hidrocol sem hidrogenação & 152,48 & 111,78 & 190,38 & 4,32 \\
\hline Óleo de babaçu refinado & 1,05 & 17,59 & 246,91 & 0,23 \\
\hline
\end{tabular}

nente ácido oléico. Quando comparado com os valores obtidos para o Hidrocol parcialmente hidrogenado e sem hidrogenação, nota-se que há coerência, pois, para óleos da família Hidrocol, a maior quantidade do ácido linoléico implicará uma maior quantidade de duplas ligações entre as moléculas de carbono $(\mathrm{C}=\mathrm{C})$.

O óleo de babaçu refinado, formado principalmente por ácido graxos saturados, apresentou, portanto, os menores índices de iodo e de acidez.

$\mathrm{O}$ espectro de infravermelho do Hidrocol parcialmente hidrogenado apresentou grandes semelhanças ao do Hidrocol sem hidrogenação (Figura 1). Não houve banda em $965 \mathrm{~cm}^{-1}$, que caracterizaria a hidrogenação (Pereira \& Brandão, 1992). O óleo parcialmente hidrogenado não apresentou características de produto que tenha sofrido hidrogenação, sugerindo reação de pequeníssima extensão.

Os dados obtidos através de flotação em bancada passaram pelo ajuste estatístico de Wills-Manser, segundo algoritmo proposto por Luz (1999).

Nas Figuras 2 e 3, referentes aos ensaios de bancada de flotação aniônica direta de apatita, estão os gráficos de recuperação e teor de $\mathrm{P}_{2} \mathrm{O}_{5}$ versus grau de saponificação dos óleos vegetais, para os minérios fosfáticos granulado e friável, respectivamente. O grau de saponificação de $55 \%$ apresentou melhores resultados de recuperação de $\mathrm{P}_{2} \mathrm{O}_{5}$ para os minérios granulado e friável. Para o minério granulado, as recuperações foram: 78,82\% com ácido oléico, 87,75\% com Hidrocol sem hidrogenação e 88,31\% com Hidrocol parcialmente hidrogenado. Para o minério friável, as recuperações foram: 57,19\% com ácido oléico, 86,87 \% com Hidrocol sem hidrogenação e 83,47 \% com Hidrocol parcialmente hidrogenado. Notam-se comportamentos muito parecidos para os dois óleos de soja da família Hidrocol, utilizados na recuperação de $\mathrm{P}_{2} \mathrm{O}_{5}$.

O grau de saponificação de $55 \%$, dos óleos, alcançou melhores resultados 
de teor de $\mathrm{P}_{2} \mathrm{O}_{5}$ no concentrado. Para o minério granulado, os teores foram: $32,87 \%$ com ácido oléico, $28,40 \%$ com Hidrocol sem hidrogenação e $29,60 \%$ com Hidrocol parcialmente hidrogenado. Para o minério friável, os teores foram: $37,15 \%$ com ácido oléico, $32,62 \%$ com Hidrocol sem hidrogenação e $35,83 \%$ com Hidrocol parcialmente hidrogenado.

Para os óleos da família Hidrocol, o teor de $\mathrm{Fe}_{2} \mathrm{O}_{3}$ sempre diminuiu com o aumento do grau de saponificação, para os dois tipos de minérios, com teores próximos a 3,50\%, para o granulado, e $1,50 \%$, para o friável, com o grau de saponificação dos óleos de $100 \%$. Os teores de $\mathrm{MgO}$, sempre abaixo de $1 \%$, e as relações $\left(\mathrm{CaO} / \mathrm{P}_{2} \mathrm{O}_{5}\right)$, com valor médio de 1,41 , não variaram consideravelmente.

As Tabelas 4 e 5 mostram os resultados dos balanços metalúrgicos referentes aos concentrados de flotação em bancada do minério fosfático granulado, etapa cleaner, respectivamente sem e com KE883B, utilizando-se os óleos no grau de saponificação de $55 \%$.

Para o ácido oléico, o teor mais elevado de $\mathrm{P}_{2} \mathrm{O}_{5}, 36,89 \%$, foi obtido na flotação sem o coletor sintético KE883B e a maior recuperação de $\mathrm{P}_{2} \mathrm{O}_{5}, 87,56 \%$, foi alcançada na flotação com KE883B. Nota-se que a adição do coletor KE883B provocou aumento da recuperação e diminuição do teor de $\mathrm{P}_{2} \mathrm{O}_{5}$ do concentrado. Também provocou aumento dos teores dos contaminantes $\mathrm{Fe}_{2} \mathrm{O}_{3}$ e $\mathrm{MgO}$, no concentrado.

Para o Hidrocol parcialmente hidrogenado, o teor de $\mathrm{P}_{2} \mathrm{O}_{5}$ e os teores dos contaminantes, obtidos nas flotações sem e com a adição do coletor sintético KE883B, apresentaram grande similaridade. A recuperação de $\mathrm{P}_{2} \mathrm{O}_{5}$ de $82,57 \%$ e o teor de $\mathrm{P}_{2} \mathrm{O}_{5}$ de $34,92 \%$, obtidos na flotação sem KE883B, foram ligeiramente superiores.

Para o Hidrocol sem hidrogenação, a adição do coletor KE883B agiu no sentido de diminuir a recuperação e aumentar o teor de $\mathrm{P}_{2} \mathrm{O}_{5}$ no concentrado.

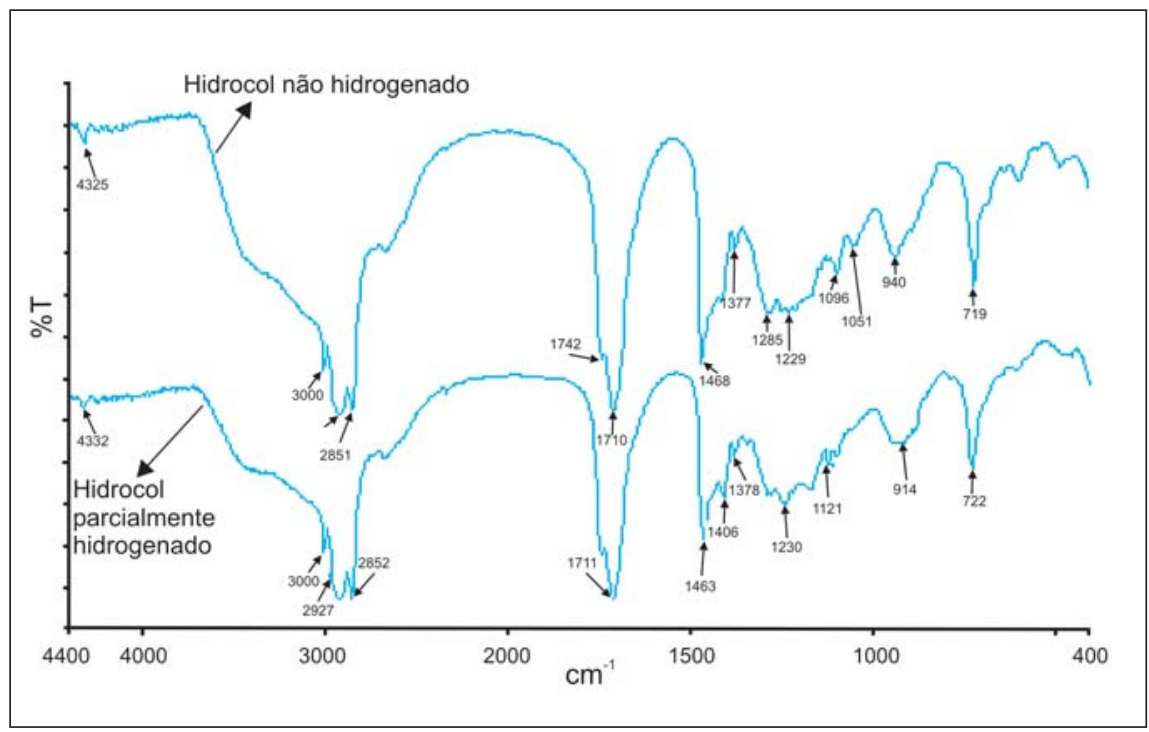

Figura 1 - Espectro de infravermelho do Hidrocol parcialmente hidrogenado e do Hidrocol sem hidrogenação.
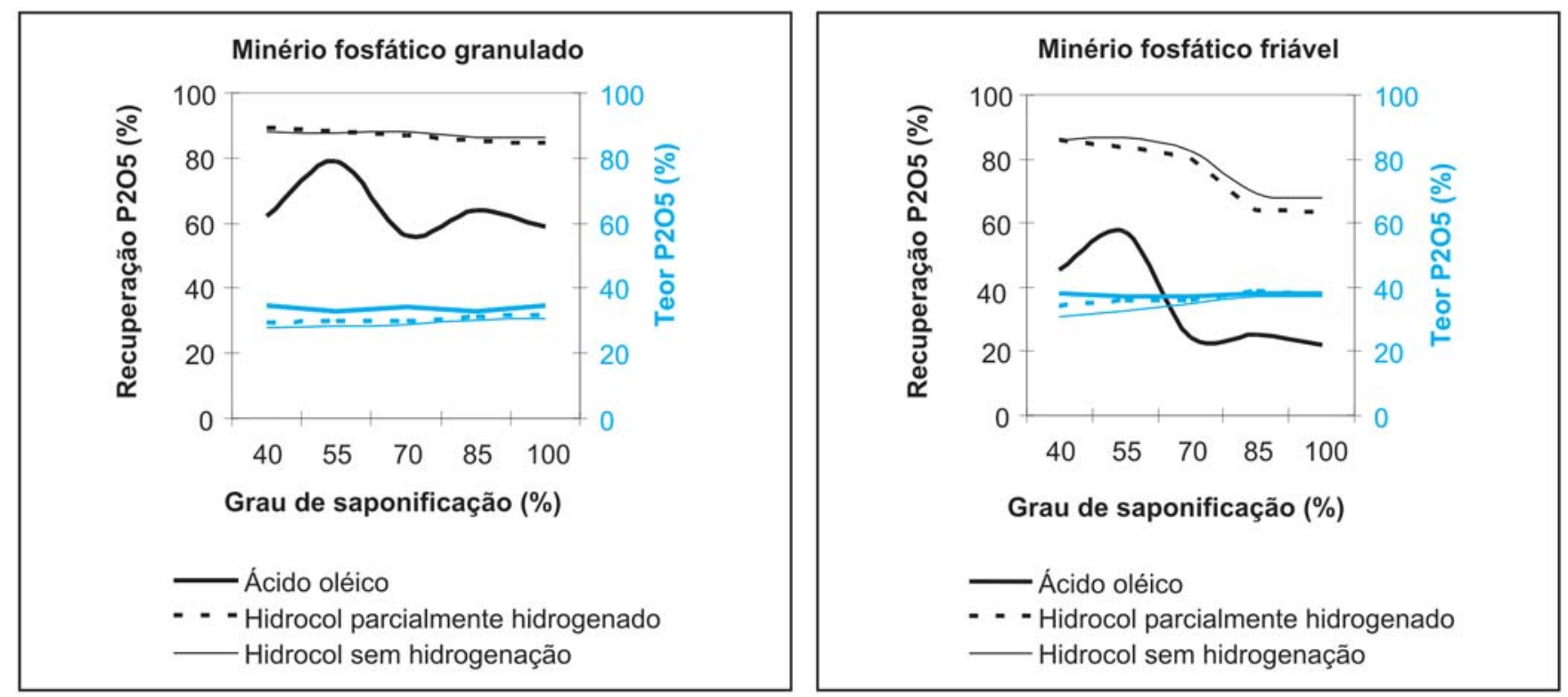

Figuras 2 e 3 - Recuperação e teor de $\mathrm{P}_{2} \mathrm{O}_{5}$ no concentrado versus grau de saponificação dos óleos vegetais para os minérios fosfáticos granulado e friável, respectivamente. 
Jardel Alves de Oliveira et al.

Os teores dos contaminantes $\mathrm{Fe}_{2} \mathrm{O}_{3}$ e $\mathrm{MgO}$, no concentrado, também diminuíram. O maior teor de $\mathrm{P}_{2} \mathrm{O}_{5}, 34,11 \%$, foi observado no concentrado da flotação com KE883B e a maior recuperação de $\mathrm{P}_{2} \mathrm{O}_{5}, 86,04 \%$, foi obtida na flotação sem o KE883B.

Para os valores de relação $\left(\mathrm{CaO} / \mathrm{P}_{2} \mathrm{O}_{5}\right)$ encontrados na flotação etapa cleaner do minério fosfático granulado, sem e com KE883B, não houve variação significativa, obtendo-se o valor médio de 1,42 .

As Tabelas 6 e 7 apresentam balanços metalúrgicos da flotação a cleaner sem e com KE883B, respectivamente, do minério friável.

Para o ácido oléico, a maior recuperação $\mathrm{P}_{2} \mathrm{O}_{5}, 80,11 \%$, foi obtida na flotação com KE883B e o teor mais elevado de $\mathrm{P}_{2} \mathrm{O}_{5}, 39,05 \%$, foi obtido no concentrado da flotação sem KE883B. A adição do coletor sintético fez os teores dos contaminantes $\mathrm{Fe}_{2} \mathrm{O}_{3}$ e $\mathrm{MgO}$ do concentrado aumentarem.
Para o Hidrocol parcialmente hidrogenado, a adição do coletor KE883B provocou diminuição da recuperação e aumento do teor de $\mathrm{P}_{2} \mathrm{O}_{5}(37,67 \%)$ no concentrado. A maior recuperação de $\mathrm{P}_{2} \mathrm{O}_{5}$, $75,64 \%$, foi obtida na flotação sem o KE883B. O teor do contaminante $\mathrm{Fe}_{2} \mathrm{O}_{3}$ no concentrado aumentou.

Para o Hidrocol sem hidrogenação, o maior teor de $\mathrm{P}_{2} \mathrm{O}_{5}$ no concentrado, $36,60 \%$, foi obtido na flotação com KE883B e a maior recuperação de $\mathrm{P}_{2} \mathrm{O}_{5}$, $80,25 \%$, foi observada na flotação sem KE883B. A adição do coletor sintético provocou diminuição dos teores dos contaminantes $\mathrm{Fe}_{2} \mathrm{O}_{3}$ e $\mathrm{MgO}$, no concentrado.

Em geral, industrialmente, trabalhase com grau de saponificação entre 55 e $75 \%$. As espécies ionizadas dos sabões estabilizam a espuma da flotação e a fração não saponificada dos óleos atua como antiespumante, auxiliando a recuperação da apatita. (Leja, 1982).

\section{Conclusões}

Os óleos "Hidrocol parcialmente hidrogenado" e "Hidrocol sem hidrogenação" possuem composições muito parecidas, sendo maior o índice de acidez no último, sugerindo presença de ácidos graxos livres em maior número. Pela espectrometria de infravermelho, nenhum dos óleos apresentou características de produto que sofreu hidrogenação, o que indica que, caso a reação tenha ocorrido, não foi completa.

Nos ensaios de flotação em bancada, etapa rougher, o Hidrocol parcialmente hidrogenado com grau de saponificação de $55 \%$ apresentou melhores resultados, levando-se em conta os teores e as recuperações de $\mathrm{P}_{2} \mathrm{O}_{5}$, as relações $\left(\mathrm{CaO} / \mathrm{P}_{2} \mathrm{O}_{5}\right)$ e os teores de $\mathrm{MgO}$ no concentrado. Para o minério granulado: $29,61 \%, 88,31 \%, 1,45$ e $0,78 \%$, respectivamente. E para o minério friável: $35,83 \%, 83,47 \%, 1,40$ e $0,35 \%$, respectivamente.

Tabela 4 - Dados referentes ao concentrado de flotação em escala de bancada, etapa cleaner e sem KE883B, do minério granulado.

\begin{tabular}{|c|c|c|c|c|c|c|c|c|c|}
\hline \multirow{2}{*}{$\begin{array}{c}\text { Óleo } \\
\text { vegetal }\end{array}$} & \multirow{2}{*}{$\begin{array}{c}\text { Grau de } \\
\text { saponificação (\%) }\end{array}$} & \multicolumn{4}{|c|}{ Teor médio (\%) } & \multicolumn{4}{|c|}{ Distribuição média (\%) } \\
\hline & & $\mathrm{P}_{2} \mathrm{O}_{5}$ & $\mathrm{Fe}_{2} \mathrm{O}_{3}$ & MgO & $\mathrm{CaO}$ & $\mathrm{P}_{2} \mathrm{O}_{5}$ & $\mathrm{Fe}_{2} \mathrm{O}_{3}$ & MgO & $\mathrm{CaO}$ \\
\hline Oléico & 55 & 36,89 & 1,15 & 0,40 & 51,30 & 62,85 & 1,26 & 3,12 & 59,60 \\
\hline Hidrocol $^{*}$ & 55 & 34,92 & 1,95 & 0,47 & 48,81 & 82,57 & 2,93 & 5,17 & 78,86 \\
\hline Hidrocol $^{\star \star}$ & 55 & 32,14 & 2,54 & 0,57 & 45,84 & 86,04 & 4,22 & 7,26 & 84,93 \\
\hline
\end{tabular}

* Hidrocol parcialmente hidrogenado.

** Hidrocol sem hidrogenação.

Tabela 5 - Dados referentes ao concentrado de flotação em escala de bancada, etapa cleaner e com KE883B, do minério granulado.

\begin{tabular}{|c|c|c|c|c|c|c|c|c|c|}
\hline \multirow{2}{*}{$\begin{array}{c}\text { Óleo } \\
\text { vegetal }\end{array}$} & \multirow{2}{*}{$\begin{array}{c}\text { Grau de } \\
\text { saponificação (\%) }\end{array}$} & \multicolumn{4}{|c|}{ Teor médio (\%) } & \multicolumn{4}{|c|}{ Distribuição média (\%) } \\
\hline & & $\mathbf{P}_{2} \mathrm{O}_{5}$ & $\mathrm{Fe}_{2} \mathrm{O}_{3}$ & MgO & $\mathrm{CaO}$ & $\mathrm{P}_{2} \mathrm{O}_{5}$ & $\mathrm{Fe}_{2} \mathrm{O}_{3}$ & MgO & $\mathrm{CaO}$ \\
\hline Oléico & 55 & 31,94 & 2,53 & 0,56 & 45,68 & 87,56 & 4,33 & 7,33 & 86,80 \\
\hline Hidrocol$^{*}$ & 55 & 34,76 & 1,99 & 0,38 & 48,63 & 82,54 & 2,89 & 4,32 & 79,43 \\
\hline Hidrocol** & 55 & 34,11 & 2,22 & 0,41 & 47,92 & 83,44 & 3,30 & 4,94 & 81,23 \\
\hline
\end{tabular}


Grau de saponificação de óleos vegetais na flotação seletiva de apatita de minério carbonatítico

Tabela 6 - Dados referentes ao concentrado de flotação em escala de bancada, etapa cleaner e sem KE883B, do minério fosfático friável.

\begin{tabular}{|c|c|c|c|c|c|c|c|c|c|}
\hline \multirow{2}{*}{$\begin{array}{c}\text { Óleo } \\
\text { vegetal }\end{array}$} & \multirow{2}{*}{$\begin{array}{c}\text { Grau de } \\
\text { saponificação (\%) }\end{array}$} & \multicolumn{4}{|c|}{ Teor médio (\%) } & \multicolumn{4}{|c|}{ Distribuição média (\%) } \\
\hline & & $\mathrm{P}_{2} \mathrm{O}_{5}$ & $\mathrm{Fe}_{2} \mathrm{O}_{3}$ & MgO & $\mathrm{CaO}$ & $\mathrm{P}_{2} \mathrm{O}_{5}$ & $\mathrm{Fe}_{2} \mathrm{O}_{3}$ & $\mathrm{MgO}$ & $\mathrm{CaO}$ \\
\hline Oléico & 55 & 39,05 & 0,52 & 0,15 & 52,86 & 38,19 & 0,26 & 0,75 & 36,12 \\
\hline Hidrocol* $^{*}$ & 55 & 37,31 & 1,28 & 0,21 & 51,54 & 75,64 & 1,34 & 2,11 & 72,28 \\
\hline Hidrocol** $^{* *}$ & 55 & 36,12 & 1,92 & 0,28 & 50,04 & 80,25 & 2,18 & 3,10 & 76,39 \\
\hline
\end{tabular}

* Hidrocol parcialmente hidrogenado.

** Hidrocol sem hidrogenação.

Tabela 7 - Dados referentes ao concentrado de flotação em escala de bancada, etapa cleaner e com KE883B, do minério fosfático friável.

\begin{tabular}{c|c|c|c|c|c|c|c|c|c}
\hline \multirow{2}{*}{$\begin{array}{c}\text { Óleo } \\
\text { vegetal }\end{array}$} & \multirow{2}{*}{$\begin{array}{c}\text { Grau de } \\
\text { saponificação (\%) }\end{array}$} & \multicolumn{4}{|c|}{ Teor médio (\%) } & \multicolumn{4}{c}{ Distribuição média (\%) } \\
\cline { 3 - 10 } & & $\mathbf{P}_{2} \mathbf{O}_{5}$ & $\mathrm{Fe}_{2} \mathbf{O}_{3}$ & $\mathbf{M g O}$ & $\mathbf{C a O}$ & $\mathbf{P}_{2} \mathbf{O}_{5}$ & $\mathbf{F e}_{2} \mathbf{O}_{3}$ & $\mathbf{M g O}$ & $\mathbf{C a O}$ \\
\hline Oléico & 55 & 36,84 & 1,66 & 0,27 & 50,70 & 80,11 & 1,86 & 3,01 & 76,74 \\
\hline Hidrocol* $^{*}$ & 55 & 37,67 & 1,40 & 0,20 & 51,71 & 74,76 & 1,43 & 1,98 & 71,60 \\
\hline Hidrocol** $^{*}$ & 55 & 36,60 & 1,80 & 0,25 & 50,56 & 78,13 & 1,95 & 2,69 & 74,56 \\
\hline
\end{tabular}

* Hidrocol parcialmente hidrogenado.

** Hidrocol sem hidrogenação.

Quanto às flotações etapa cleaner sem e com a adição de KE883B, destacam-se os resultados do Hidrocol parcialmente hidrogenado sem a adição de KE883B, avaliando-se os mesmos parâmetros apresentados anteriormente. Respectivamente, para o minério granulado: $34,92 \%, 82,57 \%, 1,40,0,47 \%$; e para o minério friável: $37,31 \%, 75,64 \%, 1,38$, $0,21 \%$.

A planta química de fertilizantes fosfatados demanda concentrado de rocha fosfática com teor de $\mathrm{P}_{2} \mathrm{O}_{5}$ de 36 a 37 $\%$ e baixos teores dos contaminantes $\mathrm{SiO}_{2}, \mathrm{Fe}_{2} \mathrm{O}_{3}, \mathrm{Al}_{2} \mathrm{O}_{3}, \mathrm{MgO}, \mathrm{CaO},(\mathrm{Oba}$, 2004). Em geral, os resultados obtidos, através dos ensaios de flotação aniônica direta de apatita, mostraram que, após a etapa cleaner realizada, utilizando-se os coletores com grau de saponificação de $55 \%$, os teores de $\mathrm{P}_{2} \mathrm{O}_{5}$ ficaram próximos ou superiores a $36 \%$; os teores de $\mathrm{MgO}$ ficaram abaixo de $0,6 \%$; os teores de $\mathrm{Fe}_{2} \mathrm{O}_{3}$ ficaram abaixo de 2,5\%; por- tanto os resultados sugerem que a saponificação dos óleos coletores em níveis elevados, próximos a $100 \%$, não necessariamente implicará a melhor condição de flotação da apatita, apenas aumentando a demanda de reagentes.

\section{Agradecimentos}

Os autores externam seu reconhecimento ao professor Paulo Roberto Gomes Brandão, da Escola de Engenharia da UFMG, pelas análises de espectrometria de infravermelho; ao professor Marco Túlio Coelho Silva do DTA-UFV, pelas análises de caracterização dos óleos, via úmida e por cromatografia gasosa; à Fosfértil e à CAPES pelo suporte a esta pesquisa.

\section{Referências bibliográficas}

BRANDÃO, P. R. G., CAIRES, L. G., QUEIROZ, D. S. B. Vegetable lipid oil-based collectors in the flotation of apatite ores. Minerals Eng., v. 7, n. 7, p. 917-925, 1994.

LEJA, J. Surface chemistry of froth flotation. New York: Plenum, 1982. p.758.

LUZ, J.A.M. Uso de vazões na compatibilização de teores via multiplicadores de Lagrange. REM - Revista Escola de Minas, v. 52, n. 4, p.269-274, 1999.

PEREIRA, A. M. T, BRANDÃO, P. R. G. Ácidos graxos insaturados (isômeros cis/trans) e saturados na flotação seletiva de minerais levemente solúveis. In: ENC. NAC. TRAT. MIN. HIDROMET., 15. Anais... São Lourenço, MG. p.19-38, 1992.

OBA, C. A. I. Fabricação de um fertilizante organo-fosfatado. Rio de Janeiro: CETEM/ MCT, 2004. Série Estudos e Documentos, 62. 35p.

Artigo recebido em 06/10/2005 e aprovado em 07/10/2006. 